\title{
CHARACTERIZATION OF PLUTONIUM AEROSOLS FROM AN INDUSTRIAL MIXED-OXIDE
}

\section{FUEL FABRICATION FACILITY}

ABSTRACT

Samples of the aerosols present in a glove box during a plutonium oxide and uranium oxide powder mixing operation were taken with a small seven-stage cascade impactor to determine the aerodynamic size distribution and concentration and with a Lovelace Aerosol Particle Separator (LAPS) to study the characteristics of the particles with respect PRINCIPAL INVESTIGATORS

O. G. Raabe

G. J. Newton

R. C. Smitha

C. J. Wilkinson

S. V. Teague

to aerodynamic equivalent size. Using alpha spectroscopy, it

was found that about $11 \%$ of the alpha activity of the aerosol was associated with ${ }^{241}$ Am. The size distributions measured with the cascade impactor had activity median aerodynamic dicometers (AMAD) equal to $1.9 \pm 0.3$ (S.D.) um and geometric standard deviations ( $\sigma_{g}$ ) equal to $1.59 \pm 0.07$ with alpha activity concentrations best expressed as log-normally distributed with median of $45 \mathrm{nCi} / 2$ and geometric standard deviation of 1.8 .

\section{INTRODUCTION}

Plutonium aerosols in a variety of physical and chemical forms are produced in various routine operations in the nuclear industry. In an untoward event these aerosols could be accidentally released from their normal containment vessels or enclosures and be inhaled by personnel working near by. A basic knowledge of the physical and chemical characteristics of these aerosols provides valuable information for evaluation of the consequences of potential accidents. Advance information concerning basic aerosol forms that are known to be present in a routine operation helps to minimize the uncertainties that usually exist following an accidental release. Adequate advance knowledge of the potential aerosol forms could also be used in the evaluation of potential therapy and decontamination procedures. Also, there is a need to compare plutonium laboratory aerosols, such as those produced at the Inhalation Toxicology Research Institute (ITRI), with plutonium aerosols found in the nuclear industry to improve the necessary extrapolation from laboratory studies to industrial situations. To these ends, a cooperative effort to sample aerosols within glove boxes at the Westinghouse Hanford Engineering and Development Laboratory (HEDL) at Richland, Washington was initiated.

\section{MATERIALS AND METHODS}

\section{Genera 1}

Two investigators went to Richland, Washington to sample the atmospheres of glove boxes in which plutonium and uranium oxide powders were being processed. Using sampling techniques and equipment developed at the ITRI, samples that were taken included seven-stage impactor samples for measurement of the aerodynamic size distribution and concentration, Lovelace Aerosol Particle Separator (LAPS) samples for study of particles with respect to aerodynamic size and point-to-point electrostatic precipitator (ESP) samples for electron-microscopy. To reduce the electrostatic charge on the aerosol particles to Boltzmann equilibrium, most samples were drawn through a concentric Kr-85 discharger (Thermo Systems, St. Paul, Minn.). Special samples were obtained for study of the shape and density characteristics of the particles by placing electron-microscope sample grids at various

\footnotetext{
Westinghouse-Hanford Engineering and Development Laboratory, Richland, Washington.
} 


\section{DISCLAIMER}

This report was prepared as an account of work sponsored by an agency of the United States Government. Neither the United States Government nor any agency Thereof, nor any of their employees, makes any warranty, express or implied, or assumes any legal liability or responsibility for the accuracy, completeness, or usefulness of any information, apparatus, product, or process disclosed, or represents that its use would not infringe privately owned rights. Reference herein to any specific commercial product, process, or service by trade name, trademark, manufacturer, or otherwise does not necessarily constitute or imply its endorsement, recommendation, or favoring by the United States Government or any agency thereof. The views and opinions of authors expressed herein do not necessarily state or reflect those of the United States Government or any agency thereof. 


\section{DISCLAIMER}

Portions of this document may be illegible in electronic image products. Images are produced from the best available original document. 
locations on the LAPS collection foils. These particles were sized from electron-micrographs by measurement of projected area diameter and calculation of count median projected area diameter (CMD) and geometric standard deviation $\left(\sigma_{g}\right)$.

Cascade impactor samples were analyzed by determining the alpha activity on each collector stage and fitting a log-normal distribution by weighted least-squares to the data. LAPS samples were analyzed by cutting the collection foil into 23 segments having different particle sizes, determining the alpha activity and least-squares fitting log-normal functions.

Solubility studies were performed at $37^{\circ} \mathrm{C}$ on six selected samples from LAPS foils using a lung fluid simulant prepared with a recipe described by Kanapilly et al. 1 both with, and without, the phosphate component. Particles from foil segments were suspended ultrasonically in deionized water which had been treated with $\mathrm{NH}_{3}$ to a pH of 10.2 and collected on a $25 \mathrm{~mm}$ diameter, $100 \mathrm{~m} \mu \mathrm{m}$ pore-size membrane filter using a vacuum filtration apparatus. Each sample filter was individually sandwiched between two clean membrane filters, mounted in a special open face plastic holder and submerged in the soivent for 10 days in individual sealed containers. The filter assembly was assayed for plutonium and americium before dissolution by X-ray counting using a CsI-NaI "phoswich" crystal system and pulse height analysis. After the ten-day dissolution period, the filter assemblies were removed and again assayed for plutonium and americium. The observed decrease in radioactivity was assumed to be proportional to the amount dissolved. All six samples of the dissolution fluid were filtered to verify that no particles had been released from the filter assemblies. Routine radiochemical procedures were used to quantitate the dissolved plutonium.

Samples of particles from the LAPS foils were prepared for alpha-spectroscopy by suspending particles ultrasonically in deionized water adjusted to $\mathrm{pH} 10.2$ with $\mathrm{NH}_{3}$. The particles were then collected on $25 \mathrm{~mm}$ diameter, $100 \mathrm{mum}$ pore-size membrane filters using a vacuum filtration apparatus. These filters were mounted on small planchets and individually placed in a spectrometer vacuum chamber having a surface-barrier solid-state alpha detector. Pulse height data were collected with a multichannel analyzer.

Description of Plant 0peration

The plant operation chosen for study involved the mixing, sieving and ball milling of oxides of plutonium and uranium as a preliminary step in the preparation of mixed-oxide fuel pellets for use in an experimental liquid metal fast breeder reactor (LMFBR). The primary ingredient in the particular mixture being prepared was plutonium dioxide; about $1 \mathrm{~kg}$ was present in the box during the operation. The plutonium dioxide had been prepared by precipitation of the oxalate and calcination of the precipitate at $750^{\circ} \mathrm{C}$ for several days. Smaller amounts of $\mathrm{UO}_{2}$ powders of both depleted uranium and $93.5 \%{ }^{235} \mathrm{U}$ enriched uranium (about $300 \mathrm{~g}$ ) were mixed with the Pu0 ${ }^{2}$. The isotope composition on a mass basis of the plutonium was given as: $0.069 \%{ }^{238} \mathrm{Pu}, 86.16 \%{ }^{239} \mathrm{Pu}, 11.61 \%{ }^{240} \mathrm{Pu}$, $1.98 \%{ }^{241} \mathrm{Pu}$ and $0.18 \%{ }^{242} \mathrm{Pu}$. Other radionuclides such as ${ }^{241} \mathrm{Am}$ and fission products were assumed to be present in trace amounts.

The operation under study was performed in a stainless steel and glass glove box designated PS-22. The volume of this enclosure was approximately $300 \mathrm{ft}^{3}$; the atmosphere was dry nitrogen metered in and out through absolute filters at a rate of about $251 /$ min so as to maintain a negative pressure of about $2.5^{\prime \prime} \mathrm{H}_{2} \mathrm{O}$ with respect to the room.

The room in which the box was housed was observed to be meticulously clean and free of radiological contamination. Although anticontamination clothing was always worn and respiratory protection was used as a precautionary measure on occasion, no alpha contamination was observed on clothing or equipment and air samples taken in the room yielded negative results when counted for plutonium. 
The operation began by the introduction into the glove box of sealed containers containing the plutonium and uranium oxide powders. The powders were weighed and placed in a pan where they were carefully mixed by hand with a spatula. The powder mixture was transferred to a mechanical stirring device and mechanically shaken to allow the granules to pass through a succession of graded screens. The process was repeated several times with each pan being cleaned with a small brush between steps.

The mixture was then placed in a ball mill which served to grind and mix the powder granules together. The powder mixture then passed through several additional sieving steps and was further mechanically mixed in a special hour-glass shaped mixing device.

Although the later steps of the fuel pellet fabrication process were not part of this study, it should be noted that eventually the powder mixture was transferred to other glove boxes where it was combined with carbowax, pressed into $0.6 \mathrm{~cm} \mathrm{D \times 1} \mathrm{cm} \mathrm{long} \mathrm{cylindrical} \mathrm{pellets} \mathrm{and} \mathrm{sintered} \mathrm{at}$ $1800^{\circ} \mathrm{C}$ for several hours. The final pellets have a physical density of $8-10 \mathrm{~g} / \mathrm{cm}^{3}$. These pellets are milled to exact specifications and eventually loaded and sealed in long stainless steel tubes which form the reactor fuel rods.

\section{Sampling Procedures}

Access into the PS-22 enclosure was obtained through a 3/4" NPT access port above the glass windows at the exhaust end of the box. The 3/4" NPT was fitted with standard compression fittings and a 1/4" 0.D. $\times 4 \mathrm{ft}$ copper tube, the end of which was placed 3 inches from the HEPA exhaust filter. Three LAPS samples at $270 \mathrm{~cm}^{3} / \mathrm{min}$ of the glove box atmosphere were obtained during the entire mixing operation. LAPS sampling times were $45 \mathrm{~min}, 60 \mathrm{~min}$ and $90 \mathrm{~min}$ on successive days, respectively. Three-minute cascade impactor samples were taken during routine operation of PS-22 also. Figure 1 is a photograph of PS-22 showing the portable LAPS in place for sampling. The cylindrical object above the LAPS is the ${ }^{85} \mathrm{Kr}$ discharger which was connected to the LAPS (or impactor) with a $2^{\prime \prime}$ long piece of tygon tubing. Cascade impactor samples were 3 min each at 450 $\mathrm{cm}^{3} / \mathrm{min}$. The two cascade impactor samples taken without the deionizer in the sampling train showed less than one-tenth the alpha activity. This discrepancy was probably the result of electrostatic charge effects.

\section{RESULTS}

Table 1 summarizes the results of the aerodynamic sizing with the cascade impactor and the LAPS of the radioactive aerosols in PS- 22 . Impactor samples taken without the ${ }^{85} \mathrm{Kr}$ discharger yielded incongruousiy low activity concentrations with high apparent median diameters; these results are probably invalid because of electrostatic effects and have not been used in the following summary.

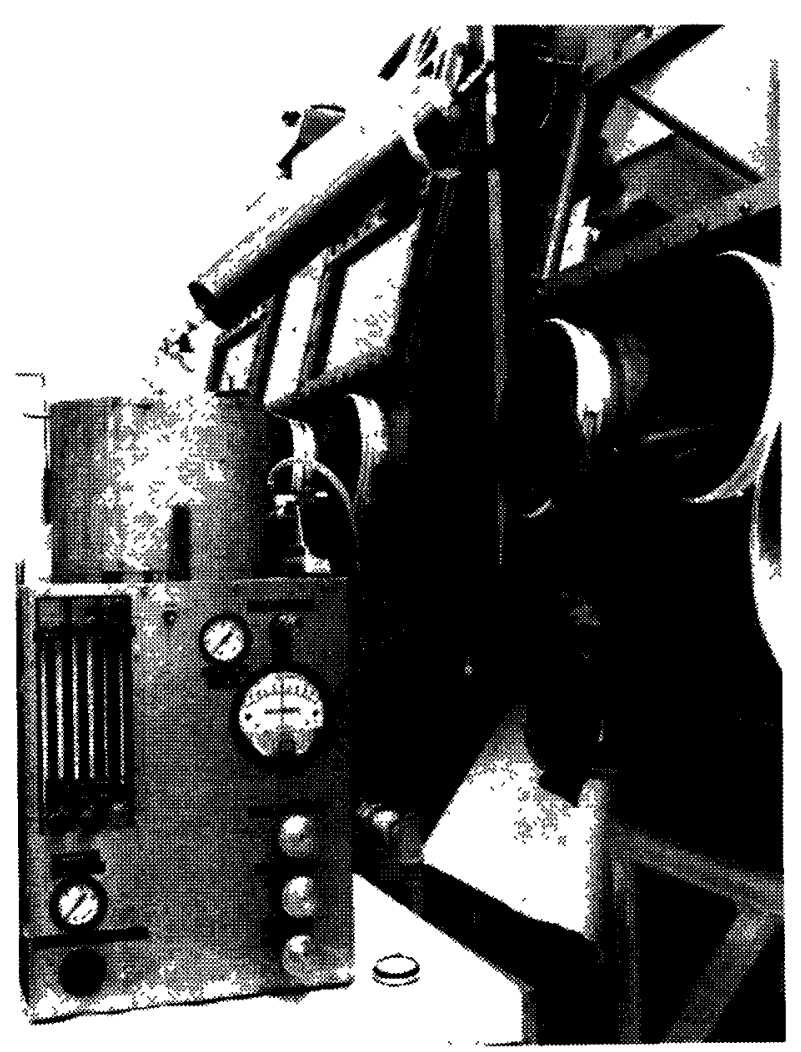

Figure 1. Portable Lovelace Aerosol Particle Separator (LAPS) used in this study in position alongside the glove box PS-22 from which the aerosol samples were taken. 
Table 1

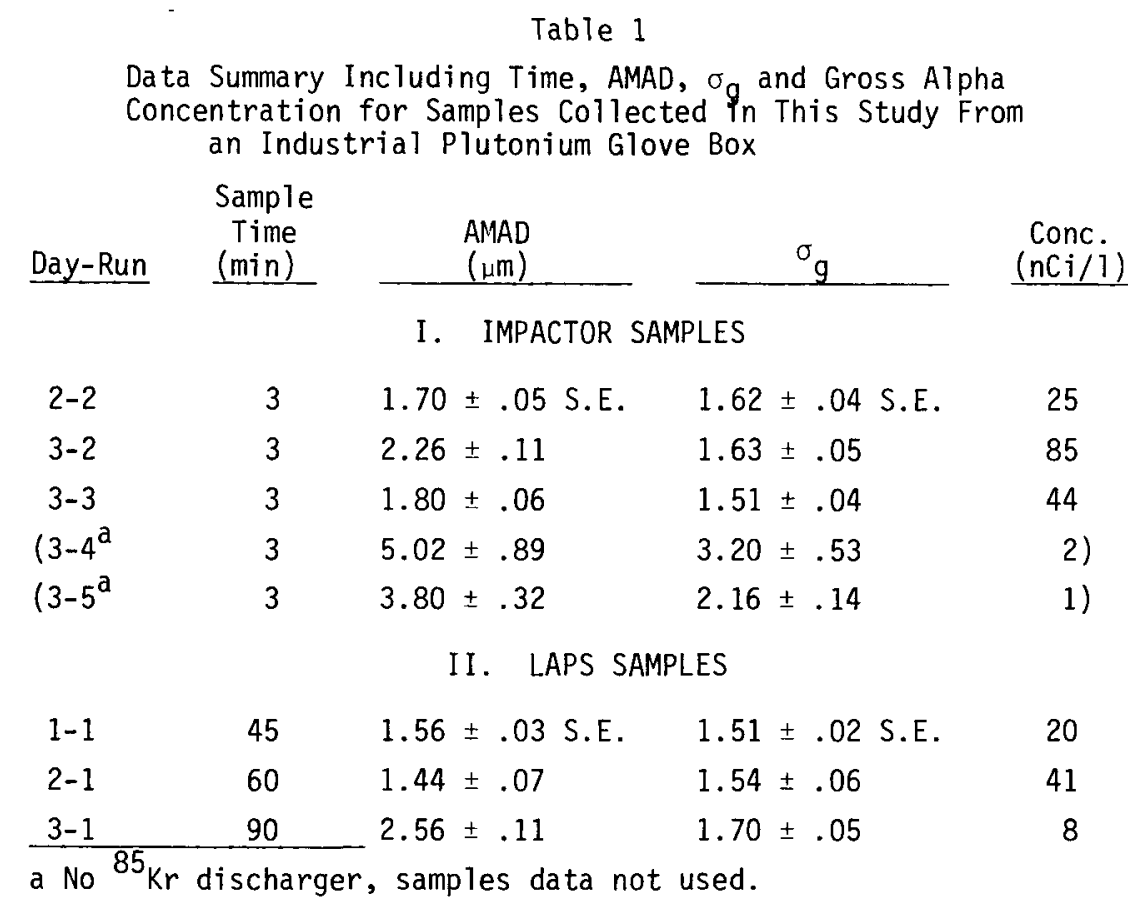

The median gross alpha activity concentration in the box determined with the impactor samples was $45 \mathrm{nCi} / 1$ with a geometric standard deviation of 1.8 . The median of all samples was $29 \mathrm{nCi} / 1$ with geometric standard deviation of 2.2. The average activity median aerodynamic diameter was 1.9 \pm 0.4 (S.D.) $\mu \mathrm{m}$ with geometric standard deviation $\left(\sigma_{g}\right)$ equal to $1.59 \pm 0.08$ (S.D.) from all samples.

Alpha spectroscopy was done on all LAPS samples of sample number 2-1. These results showed that the alpha activity was associated with two distinct energy peaks, one representing the $239-$ ${ }^{240} \mathrm{Pu}$ (5.1 Mev), one representing ${ }^{238} \mathrm{Pu}$ and ${ }^{241} \mathrm{Am}$ (5.5 Mev). Using the known plutonium isotopic ratios, the ${ }^{241}$ Am activity was calculated to be $11 \%$ of the gross alpha activity. The age of the plutonium since chemical separation was calculated to be 3.2 years based upon the ${ }^{241} \mathrm{Am} /{ }^{241} \mathrm{Pu}$ activity ratio.

Examples of particle samples collected with the ESP and at various locations in the LAPS are shown in Figure 2. Particle density calculations based upon the LAPS-collected particles assuming the shape factor of spheres are summarized in Table 2. The observed densities of larger particles were higher than for small particles. also the observed densities were much lower than the theoretical density of $11.3 \mathrm{~g} / \mathrm{cm}^{3}$ for $\mathrm{PuO}_{2}$ indicating that the particles were porous conglomerates of smaller particles.

Although the in vitro dissolution experiments are not completed, preliminary indications are that the cumulative plutonium solubility is higher in the standard solvent both with and without phosphate than observed for laboratory aerosols of ${ }^{239} \mathrm{PuO}_{2}$. The cumulative solubility of americium in the phosphate free solvent is at least two orders of magnitude higher than that of plutonium but is much less in the solvent with phosphate as was also observed with laboratory aerosols of ${ }^{241_{A m O}} 2$ (this report, pp. 1-7).

\section{DISCUSSION}

The concentrations of plutonium aerosols in the enclosure PS-22 were found to be about $10^{7}$ times the ICRP maximum permissible air concentration, demonstrating the utility of use of the safety enclosure in these industrial operations. The aerosols were found to have aerodynamic size distributions in the respirable range with optimum potential deep lung deposition if inhaled (about $20 \%$ ). 


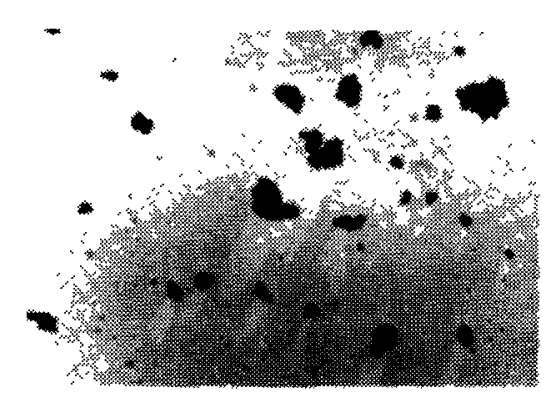

ES.P.

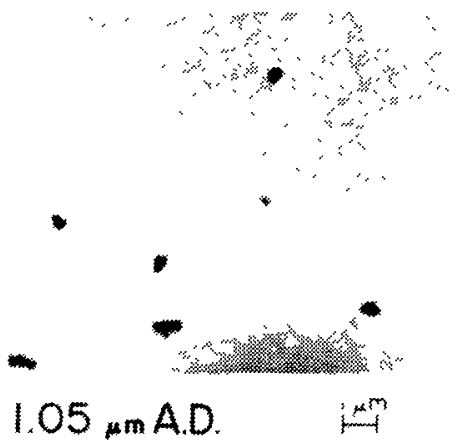

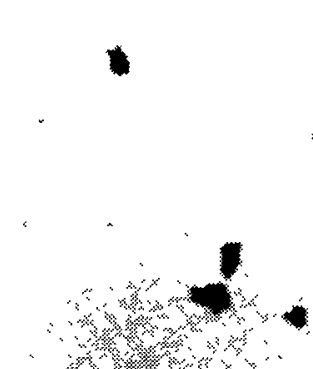

I. $3 \mu \mathrm{mA.D}$.

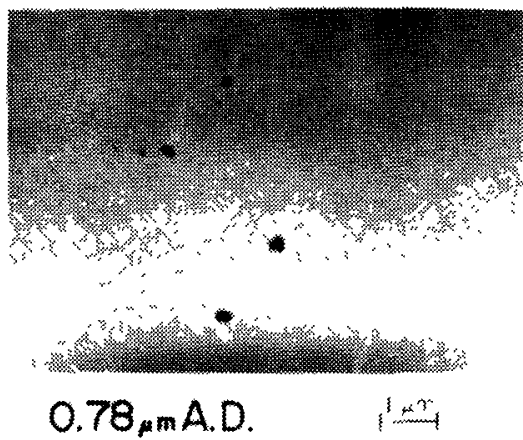

Figure 2. Electron-micrographs of samples of the plutonium oxide and uranium oxide aerosols collected in this study including a polydisperse sample collected with the electrostatic precipitator (ESP) and three aerodynamically monodisperse sizes collected with the LAPS.

Table 2

Surmary of Data Used in Determining the Effective Density ( $\rho$ ) Including Number of Samples ( $n)$, Aerodynamic Diameter (AD), Count Median Projected Area Diameter (CMD) and Associated Geometric Standard Deviation $\left(\sigma_{g}\right)$ for Each LAPS Position With Appropriate Standard Deviations of Aerosols Collected From an Industrial Plutonium Glove Box

LAPS

\begin{tabular}{|c|c|c|c|c|c|}
\hline $\begin{array}{l}\text { Position } \\
(\mathrm{cm}) \\
\end{array}$ & $\begin{array}{c}\mathrm{AD} \\
(\mu \mathrm{m}) \\
\end{array}$ & $\underline{n}$ & $\begin{array}{l}\text { CMD } \\
(\mu \mathrm{m})\end{array}$ & $\sigma_{g}$ & $\left(\mathrm{gm} / \mathrm{cm}^{3}\right)$ \\
\hline 15 & 1.3 & 9 & $0.41 \pm .03$ & $1.32 \pm .14$ & $7.3 \pm 1.1$ \\
\hline 20 & 1.05 & 7 & $0.36 \pm .04$ & $1.32 \pm .11$ & $6.0 \pm 1.3$ \\
\hline 30 & 0.78 & 9 & $0.33 \pm .11$ & $1.28 \pm .14$ & $4.2 \pm 1.7$ \\
\hline 40 & 0.64 & 3 & $0.27 \pm .03$ & $1.44 \pm .12$ & $3.5 \pm 0.6$ \\
\hline Overall & & 28 & & & $5.6 \pm 1.9$ \\
\hline
\end{tabular}

When compared to laboratory aerosols the industrial aerosols of plutonium (and incorporated americium) oxide had much lower effective physical densities and higher dissolution rates, suggestive of particle porosity and high surface to mass ratios.

\section{REFERENCES}

1. Kanapilly, G. M., 0. G. Raabe, C. H. T. Goh and R. A. Chimenti, "Measurement of In Vitro Dissolution of Aerosol Particles for Comparison to In Vivo Dissolution in the Lower Respiratory Tract After Inhalation," Health Phys. 24:497-507, 1973. 